\title{
Differences in Induced Volatile Emissions among Rice Varieties Result in Differential Attraction and Parasitism of Nilaparvata lugens Eggs by the Parasitoid Anagrus nilaparvatae in the Field
}

\author{
Yonggen Lou • Xiaoyan Hua • Ted C. J. Turlings • \\ Jiaan Cheng • Xuexin Chen • Gongyin Ye
}

Received: 30 March 2006 / Revised: 20 May 2006 /

Accepted: 21 June 2006 / Published online: 24 October 2006

(C) Springer Science + Business Media, Inc. 2006

\begin{abstract}
We compared the volatiles of JA-treated plants of six rice varieties and then determined, in the laboratory and field, if they differed in attractiveness to Anagrus nilaparavate Pand et Wang, an egg parasitoid of rice planthoppers. Analyses of volatiles revealed significant differences among varieties, both in total quantity and quality of the blends emitted. On the basis of these differences, the six varieties could be roughly divided into three groups. In a Y-tube olfactometer, female wasps preferred odors from two groups. These preferences corresponded to observed parasitism rates in a field experiment. A comparison of the volatiles with results from behavioral assays and field experiments indicates that the quality (composition) of the blends is more important for attraction than the total amount emitted. The results imply that the foraging success of natural enemies of pests can be enhanced by breeding for crop varieties that release specific volatiles.
\end{abstract}

Keywords Rice - Anagrus nilaparavate - Nilaparvata lugens $\cdot$ Induced plant volatiles · Jasmonic acid · Volatiles variability · Host-searching behavior · Parasitism · Parasitoid

\section{Introduction}

It is widely recognized that herbivore-induced plant volatiles play an important role in host/ prey searching behavior of predators and parasitoids of herbivores (Vet and Dicke, 1992; Dicke, 1999; Turlings and Wäckers, 2004). The release of these attractants can also be

Y. Lou $(\bowtie) \cdot X$. Hua $\cdot$ J. Cheng $(\bowtie) \cdot X$. Chen $\cdot$ G. Ye

Institute of Insect Sciences, Zhejiang University, Hangzhou, 310029, China

e-mail: yglou@zju.edu.cn

e-mail: jacheng@zju.edu.cn

Y. Lou • T. C. J. Turlings

Institute of Biology, University of Neuchatel, Neuchatel, Switzerland 
achieved by wounding the plants and applying herbivore regurgitant or elicitors such as jasmonates (JA) to the damaged sites (Turlings et al., 1993a; Hopke et al., 1994; Halitschke et al., 2001). Induced volatile blends vary considerably in quantity and quality with plant species or variety (Takabayashi and Dicke, 1996; Krips et al., 2001; Fritzsche-Hoballah et al., 2002; Degen et al., 2004; Van Den Boom et al., 2004; Bukovinszky et al., 2005), which may reflect in differences in attractiveness to the natural enemies of herbivores (Krips et al., 2001; Fritzsche-Hoballah et al., 2002; Bukovinszky et al., 2005). However, little to nothing is known about the consequences of these differences among plant genotypes for the effectiveness of the natural enemies in the field.

Nilaparvata lugens is one of the most important rice pests. It feeds on the phloem and causes a decrease in leaf area, plant height, dry weight, leaf and stem nitrogen concentration, chlorophyll contents, and photosynthetic rate (Rubia-Sanchez et al., 1999; Watanabe and Kitagawa, 2000), which subsequently results in yield loss. Previous studies have shown that $N$. lugens attack or JA treatment alters the volatile profiles of rice plants, and these volatiles are strongly attractive to the egg parasitoid Anagrus nilaparvatae (Lou et al., 2005a,b), a major natural enemy of the rice planthoppers (Cheng and He, 1996). Moreover, the parasitism of $N$. lugens eggs by A. nilaparvatae on plants that were surrounded by JA-treated plants is more than twofold higher than on control plants in the greenhouse and field (Lou et al., 2005a), implying that augmenting the release of rice-produced attractants has the potential to enhance the effectiveness of the parasitoid in the control of $N$. lugens. This should be testable, as the volatiles released from different rice varieties in response to $N$. lugens infestation show distinct differences in attraction of the parasitoid (Ma et al., 2004). In this work, we performed such tests, whereby we compared the volatile emissions of various rice varieties after JA induction, as well as their attractiveness to A. nilaparvatae in the laboratory and field.

\section{Methods and Materials}

\section{Plant Growth}

Rice varieties used in this study were TN1, IR26, IR64, Xiushui 63, Bing 97-34, and Bing 97-59, whose genetic backgrounds are described in Table 1. Of these varieties, both IR26 and IR64 contain the Bphl gene (Zhu et al., 2004), a resistance-related gene to biotype one of $N$. lugens, and share several parents in their pedigrees; the other four are all susceptible to $N$. lugens, and three (Xiushui 63, Bing 97-34, and Bing 97-59) have a similar genetic background (Table 1). Pregerminated seeds were sown in a greenhouse, and after 20-25 d,

Table 1 Genetic background of six rice varieties

\begin{tabular}{ll}
\hline Variety & Genetic background \\
\hline TN $_{1}$ & DGWG/Tsai Yuan Chan \\
IR26 & IR24/TKM6; containing Bph1 gene \\
IR64 & ...IR24/TKM6...IR5657-33-2-1/IR2061-465-1-5-5; containing Bph1 gene \\
Xiushui 63 & Shan 41r/Bing 8961//Bing 8961(M) \\
Bing 97-34 & Bing 8961/Bing 93390 \\
Bing 97-59 & Bing 9147/Bing 9117//Bing 88122(M)/3/Xiushui 63(F) \\
\hline
\end{tabular}

" /," " //," and " /3/" indicate the first, second, and third hybridization, respectively. For each cross, the female parent is listed first unless otherwise specified. F, female parent; M, male parent. 
seedlings were transplanted into small clay pots $[8 \mathrm{~cm}($ diam $) \times 10 \mathrm{~cm}$ (height) $]$ each with one plant, or big clay pots $(16 \times 10 \mathrm{~cm})$ each with three plants. In the latter, plants were arranged in an equilateral triangle $8 \mathrm{~cm}$ apart. Plants were watered daily, and each pot was supplied with $10 \mathrm{ml}$ of nutrient solution $\left(\mathrm{Ca}\left(\mathrm{NO}_{3}\right)_{2} \cdot 4 \mathrm{H}_{2} \mathrm{O}, 0.5 \mathrm{~g} / \mathrm{l} ; \mathrm{K}\left(\mathrm{NO}_{3}\right)_{2} \cdot 4 \mathrm{H}_{2} \mathrm{O}, 0.125 \mathrm{~g} / \mathrm{l}\right.$; $\left.\mathrm{MgSO}_{4} \cdot 7 \mathrm{H}_{2} \mathrm{O}, 0.125 \mathrm{~g} / \mathrm{l} ; \mathrm{K}_{2} \mathrm{HPO}_{4}, 0.125 \mathrm{~g} / \mathrm{l} ; \mathrm{FeCl}_{2}, 0.005 \mathrm{~g} / \mathrm{l}\right)$ every $3 \mathrm{~d}$. All plants were placed in a controlled climate room that was maintained at $23 \pm 2^{\circ} \mathrm{C}, 70 \% \mathrm{r}$.h. and $18 \mathrm{hr}$ photophase $(25,000 \mathrm{~lx})$. Twenty-five to $30 \mathrm{~d}$ after potting, plants were used for experiments. Plantings were continued at regular intervals so that enough of suitable age were available for all experiments.

Insects

The $N$. lugens culture was originally obtained from the China National Rice Research Institute (CNRRI), Zhejiang, and maintained on Shanyou 63 rice plants (susceptible to $N$. lugens) in a greenhouse. Late instar nymphs of $N$. lugens were captured from the greenhouse and reared on potted Shanyou 63 rice plants, which were confined in plastic cages $(11 \times 40 \mathrm{~cm})$. Caged rice plants were maintained in a controlled climate room at $28 \pm$ $2{ }^{\circ} \mathrm{C}, 12 \mathrm{hr}$ photophase, and $70-80 \% \mathrm{r}$. h. Newly emerged adults of $N$. lugens were collected daily and fed on potted fresh Shanyou 63 rice plants. With this procedure, $N$. lugens adults of uniform age were obtained.

A laboratory colony of the egg parasitoid A. nilaparvatae was started from individuals trapped in rice fields in Hangzhou, using Shanyou 63 rice plants with $N$. lugens eggs as bait. The colony was propagated on $N$. lugens eggs in rice shoots enclosed in glass tubes $(2.5 \times 20 \mathrm{~cm})$, which were kept in a controlled climate room at $28 \pm 2{ }^{\circ} \mathrm{C}, 12 \mathrm{hr}$ photophase, and $70-80 \%$ r.h. Each day, newly emerged wasps were collected into clean glass tubes $(2.5 \times 20 \mathrm{~cm})$ with access to both water and honey solution, and held for at least $2 \mathrm{hr}$ to ensure mating. From the second generation onwards, female parasitoids were used in experiments less than $24 \mathrm{hr}$ after emergence.

\section{Plant Treatment}

Potted plants ( 1 or 3 per pot) were washed with running water. They were individually damaged with a needle at the lower and upper positions of the rice stems, each with 200 pricks. They were subsequently treated by applying $20 \mu \mathrm{l}$ of $10 \mathrm{mM}$ jasmonic acid in $50 \mathrm{mM}$ sodium phosphate buffer (titrated with $1 \mathrm{M}$ citric acid until $\mathrm{pH}=8$ ) at each damage site (JA). In a previous study, we found that JA treatment induces the release of volatiles in rice, resulting in the attraction of the parasitoid (Lou et al., 2005a). Plants were treated at 17:00 $\mathrm{hr}$, and then the plants were placed in a controlled climate room that was maintained at $28 \pm 2{ }^{\circ} \mathrm{C}, 12 \mathrm{hr}$ photophase, and $80 \%$ r.h. Fifteen hours after treatment, i.e., at 8:00 hr the next day, plants were used for experiments.

\section{Collection, Isolation and Identification of Volatile Compounds}

The volatile collection system has been described in detail (Turlings et al., 1998). It basically consists of six vertically placed cylindrical glass tubes $(9.5 \mathrm{~cm}$ i.d., $54 \mathrm{~cm} \mathrm{high})$. A split Teflon plate with a hole in the center at the base of a cylinder was filled loosely around the plant stem, allowing the separation of the aerial part of the plant, in the cylinder, from the pot, which remained outside (Turlings et al., 1998). Purified and humidified air was pushed into each cylinder at a rate of $11 / \mathrm{min}$ and passed over the plant. Around the base of 
each cylinder, just above the Teflon disk, eight openings served as ports that could hold the collection traps. Only one port was used during an experiment. For collections, air was pulled (0.8 1/min) through a Super-Q adsorbent trap (Heath and Manukian, 1992), whereas the rest of the air was vented out through the hole in the bottom, thus preventing outside, impure air from entering. The automated part of the collection system (Analytical Research System, Gainesville, FL, USA) controlled the flow through the trap. The climate chamber (CMP4030; CONVIRON, Winnipeg, Manitoba, Canada) in which the collection cylinders were housed was kept at $17.5^{\circ} \mathrm{C}$; due to heat irradiation, the temperature inside the cylinders was $23 \pm 3^{\circ} \mathrm{C}$. During the light cycle, light intensity was about $20,000 \mathrm{lumen} / \mathrm{m}^{2}$.

Volatiles emitted from plants of the six varieties that were wounded and treated with JA were collected. Collections started immediately after the lights were turned on, $15 \mathrm{hr}$ after treatment, and lasted $4 \mathrm{hr}$. After each collection, traps were extracted with $150 \mu \mathrm{l}$ of methylene chloride (Lichrosolv.; Merck, Whitehouse Station, NJ, USA) and 200 ng of $n$-octane and nonyl acetate (Sigma, Buchs, Switzerland) in $10 \mu$ of methylene chloride were added to the samples as internal standards. Collections were replicated six times for each variety.

Analyses were done with an HP 6890 series gas chromatograph equipped with an automated on-column injection system (HP G1513 A) and a flame ionization detector. A 3- $\mu$ l aliquot of each sample, was injected onto an apolar SE-30 capillary column $(30 \mathrm{~m}, 0.25 \mathrm{~mm}$ i. d., $0.25 \mu \mathrm{m}$ film thickness; Alltech, Deerfield, IL, USA) that was preceded by a deactivated retention gap $(5 \mathrm{~m}, 0.25 \mathrm{~mm}$ i.d.) and a deactivated precolumn $(30 \mathrm{~cm}, 0.530 \mathrm{~mm})$. Helium $(24 \mathrm{~cm} / \mathrm{sec})$ was used as carrier gas. After injection, the column temperature was maintained at $40^{\circ} \mathrm{C}$ for $3 \mathrm{~min}$, increased to $230^{\circ} \mathrm{C}$ at $8^{\circ} \mathrm{C} / \mathrm{min}$, and held at $230^{\circ} \mathrm{C}$ for $9.5 \mathrm{~min}$. The detector signal was processed with HP GC Chemstation software. Compounds were identified by comparison of GC retention times with those from our previous studies (Lou et al., 2005a) and those of authentic standards.

\section{Olfactometer Bioassay}

Responses of $A$. nilaparvatae females to rice volatiles were measured in a Y-tube olfactometer. The olfactometer consisted of a Y-shaped glass tube (1 cm diam). The base and the two arms of the $\mathrm{Y}$ tube were all $10 \mathrm{~cm}$ in length. Each arm was connected to an odor source container (a glass cylinder, $6 \times 46 \mathrm{~cm}$ ). An airstream was generated and was divided in two, and each secondary airstream was led through a flowmeter, a tube with active charcoal, a humidifier bottle, and one of the odor containers. Subsequently, the two airstreams were led through the two arms of the Y-tube olfactometer at $150 \mathrm{ml} / \mathrm{min}$. The Y-tube olfactometer was placed in a box painted white with an artificial light source consisting of two $20-\mathrm{W}$ fluorescent lamps placed in front of the box. All bioassays were conducted between 09:00 and 17:00 hr. During experiments, the temperature in the room was maintained at $25-28^{\circ} \mathrm{C}$.

The six varieties were divided into three groups on the basis of the volatiles profiles that they emitted after JA treatment (Table 2; Fig. 2): group 1 (TN1), group 2 (IR26 and IR64), and group 3 (Bing 97-34, Bing 97-59, and Xiushui 63). To compare attractiveness among and within these groups, we selected the following five pairs for olfactometer tests: IR26 vs. IR64, Bing 97-59 vs. Xiushui 63, TN1 vs. IR26, Bing 97-59 vs. IR26, TN1 vs. Bing 97-59. Fifteen hours after JA treatment, 10 individually potted plants of each variety were cut off at soil level, their cut stems wrapped in wet cotton, and the plants of one variety were placed into one of the odor source containers. Mated female parasitoids were introduced individually into the base tube of the Y-shaped olfactometer and given $10 \mathrm{~min}$ to walk towards the end of one of the arms. A choice for an odor source was defined as a female crossing a line $7 \mathrm{~cm}$ after the division of the base tube and remaining there for at least $1 \mathrm{~min}$. 


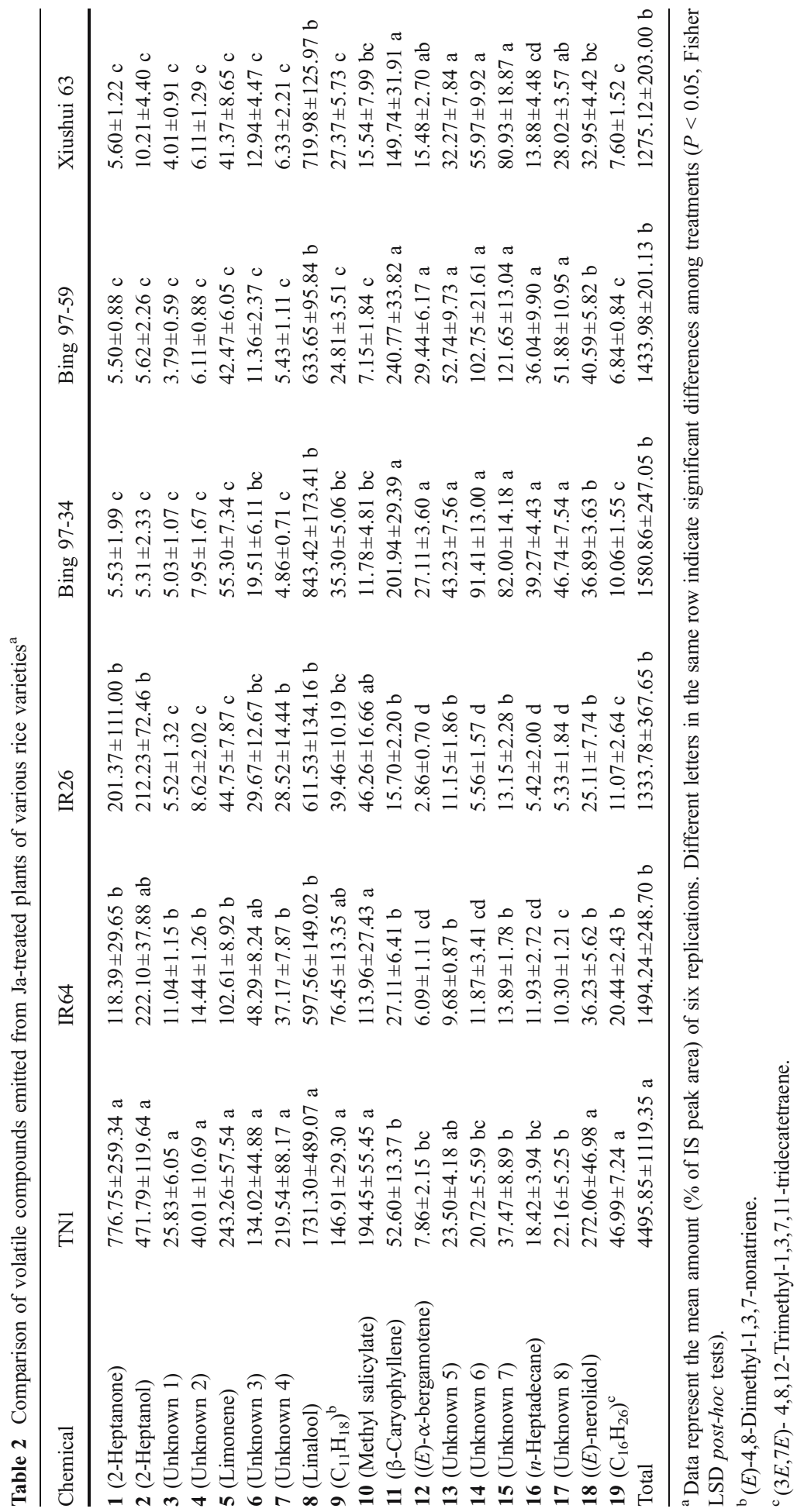


If a parasitoid did not make a choice within $10 \mathrm{~min}$, this was recorded as "no response." After two females were tested, the olfactometer tube was washed with $98 \%$ alcohol and heated at $80^{\circ} \mathrm{C}$ for several minutes. To eliminate the effects of asymmetrical bias, connections of the two arms of the olfactometer to the odor source containers were exchanged after testing of two females, and the odor source containers were exchanged and supplied with a new set of plants after testing of eight females. For each odor source combination, at least 48 females were tested. All females that were tested made a choice.

\section{Field Experiment}

To obtain plants with $N$. lugens eggs, plants of the variety Shanyou 63 were individually infested for $1 \mathrm{~d}$ with 10 gravid $N$. lugens females that were confined to the plants in two parafilm bags at the upper and lower positions of the stems. Of these plants, two were chosen with about 80-100 1-d-old $N$. lugens eggs, and they were transplanted to a pot into the center of a triangle of three plants of a particular variety, which had been wounded and treated with $10 \mathrm{mM} \mathrm{JA} 15 \mathrm{hr}$ earlier (Fig. 1A). Five pots for each of the varieties-TN1, IR26, IR64, Bing 97-59, and Xiushui 63-were placed at five locations in a rice field (20 m wide, $35 \mathrm{~m}$ long; rice variety Jialeyou 2) as shown in Fig. 1B. Hence, each location included five pots, each of them with JA-treated plants of a different variety. Two days after the plants were introduced into the rice field, they were transferred to the controlled climate room at $28 \pm 2{ }^{\circ} \mathrm{C}, 12 \mathrm{hr}$ photophase, and $80 \%$ r.h. Each pot of plants was confined to an $11 \times 40 \mathrm{~cm}$ plastic cage (after herbivores, predators, and parasitoids had been removed). Five days later, the plants were cut off at soil level and dissected under a microscope to record the total and parasitized $N$. lugens eggs by using the method described in Lou et al. (2005a). This experiment was done two times (July 6 and September 27, 2005).

Fig. 1 Design of potted plants for field experiment (A) and arrangement of plants in a rice field (B). Letters a, b, and c represent three plants that were arranged in an equilateral triangle $8 \mathrm{~cm}$ apart and were wounded and treated with $40 \mu \mathrm{l}$ of $10 \mathrm{mM}$ $\mathrm{JA}$ in $50 \mathrm{mM}$ sodium phosphate buffer $(\mathrm{pH}=8)$; $\mathrm{d}$ and e are two plants of variety Shanyou 63, each with 80-100 N. lugens eggs, which were planted into the center of the triangle. Numbers indicate locations, and each location included five pots of plants, each with JA-treated plants of one of the five varieties: TN1, Bing 9734 , Xiushui 63, IR26 or IR64

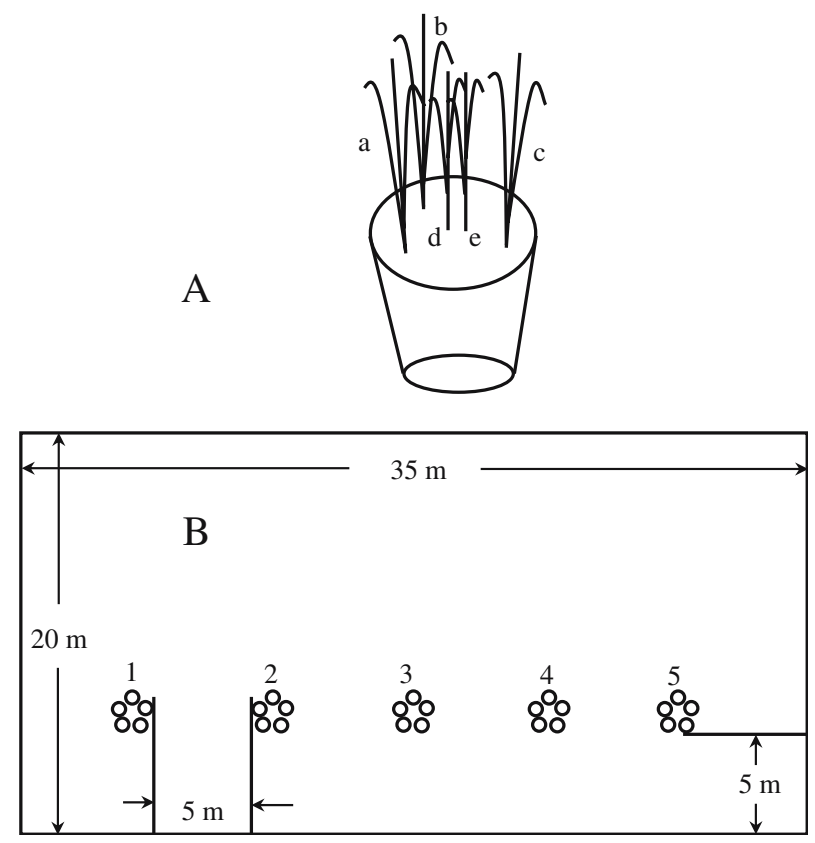




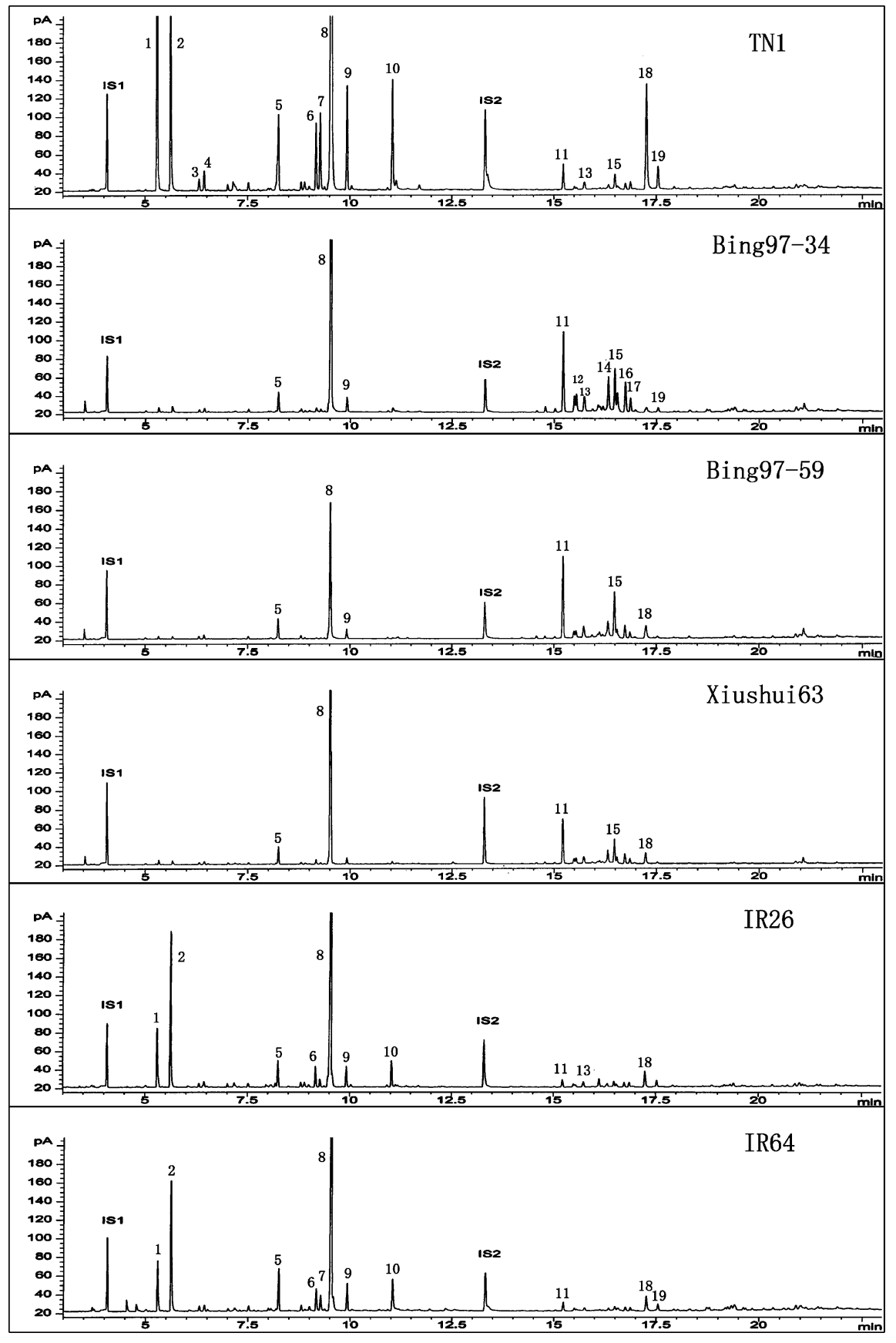

Fig. 2 Typical chromatograms obtained from headspace collections from JA-treated rice plants of rice variety TN1, Bing 97-34, Bing97-59, Xiushui 63, IR26 and IR64. 1, 2-Heptanone; 2, 2-heptanol; 3, unknown $1 ; \mathbf{4}$, unknown $2 ; \mathbf{5}$, limonene; $\mathbf{6}$, unknown $3 ; \mathbf{7}$, unknown $4 ; \mathbf{8}$, linalool; $\mathbf{9},(E)$-4,8-dimethyl-1,3,7nonatriene; 10, methyl salicylate; 11, $\beta$-caryophyllene; 12, $(E)$ - $\alpha$-bergamotene; $\mathbf{1 3}$, unknown $5 ; \mathbf{1 4}$, unknown 6 ; 15, unknown 7; 16, $n$-heptadecane; 17, unknown $8 ; \mathbf{1 8}$, $(E)$-nerolidol; 19, $(3 E, 7 E)$ - 4,8,12-trimethyl$1,3,7,11$-tridecatetraene 


\section{Data Analysis}

Differences in behavioral responses of the parasitoid to pairs of JA-induced rice volatiles of various varieties were determined by $\chi^{2}$ tests. To test for differences in parasitism among varieties, we used the Friedman rank sum test. Comparison of the data on plant volatiles were analyzed by analysis of variance (ANOVA) after the data were log-transformed. If the ANOVA analysis was significant $(P<0.05)$, Fisher LSD post-hoc tests to detect significant differences among groups were conducted. Data were analyzed with Statistica (Statistica, SAS, Institute Inc., Cary, NC, USA).

\section{Results}

\section{Volatiles Comparison}

The analyses revealed significant differences in volatile profiles emitted from JA-treated plants of the six varieties (Table 2; Fig. 2). The total amount emitted from TN1 was significantly (from 2.84 to 3.53 times) higher than those from the other five varieties, whereas no differences in total amounts were found among the remaining varieties. The volatile profiles of the six varieties could be roughly divided into three groups. The first group represented the volatiles released from TN1 plants, which, in addition to the total amount, had the highest amount of compounds 2-heptanone, 2-heptanol, limonene, linalool, (E)-4,8-dimethyl-1, 3, 7-nonatriene, $(E)$-nerolidol, (3E,7E)-4,8,12-trimethyl-1,3,7,11-tridecatetraene, and unknowns 1, 2, 3, and 4 (Table 2; Fig. 2). The second group consisted of varieties IR64 and IR26 plants. In this group, plants usually released intermediate amount of 2-heptanone, 2-heptanol, and unknown 4, and the lowest levels of $(E)$ - $\alpha$-bergamotene, $n$ heptadecane, and unknowns 6 and 8. The third group included Bing 97-34, Bing 97-59, and Xiushui 63 (Table 2; Fig. 2). They usually had the highest levels of $\beta$-caryophyllene, $(E)$ - $\alpha$-bergamotene, $n$-heptadecane, unknowns $\mathbf{5}, \mathbf{6}, \mathbf{7}$, and $\mathbf{8}$, and the lowest levels of 2heptanone, 2-heptanol, unknown 4, methyl salicylate and $(3 E, 7 E)$ - 4,8,12-trimethyl1,3,7,11-tridecatetraene (Table 2; Fig. 2).

\section{Olfactometer Bioassay}

We compared the choices of female A. nilaparvatae when offered pairs of odors within groups and between groups. When the parasitoid was exposed to volatiles from pairs of

Fig. 3 Number of Anagrus nilaparvatae female adults attracted by volatiles released from JAtreated plants of pairs of varieties: plants were used $15 \mathrm{hr}$ after they were wounded and treated with $40 \mu \mathrm{l}$ of $10 \mathrm{mM} \mathrm{JA}$ in $50 \mathrm{mM}$ sodium phosphate buffer $(\mathrm{pH}=$ 8). Asterisks indicate significant differences between members of a pair $\left(P<0.05, \chi^{2}\right.$ test $)$

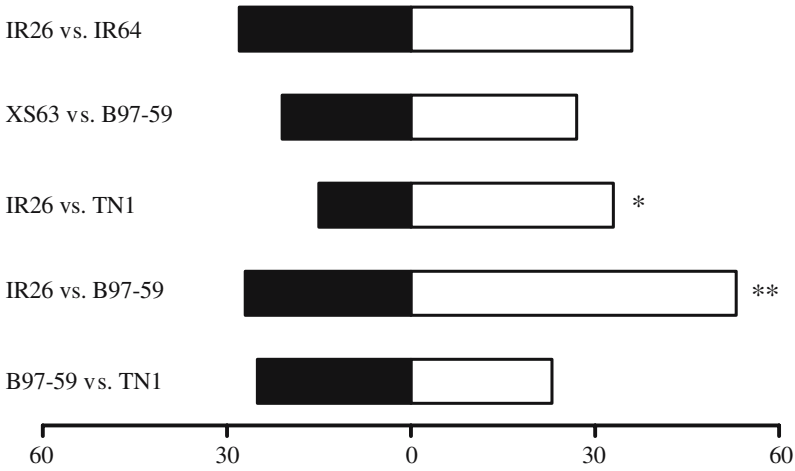

No. of the parasitoid to the odor 
Fig. 4 Mean $( \pm \mathrm{SE})$ parasitism rates (\%) of Nilaparvata lugens eggs by Anagrus nilaparvatae in the field on Shanyou 63 rice plants of that were surrounded by JA-treated plants of variety $\mathrm{TN} 1$, Bing 97-59 (B97-59), Xiushui 63 (XS63), IR26, or IR64. Plants were placed in the field for 2 days on September $(\mathrm{A}, N=5)$ or October $(\mathrm{B}, N=5), 15 \mathrm{hr}$ after they were wounded and treated with $40 \mu \mathrm{l}$ of $10 \mathrm{mM} \mathrm{JA}$ in $50 \mathrm{mM}$ sodium phosphate buffer $(\mathrm{pH}=8)$. The differences in parasitism among the varieties were determined by Fieldman rank sum test

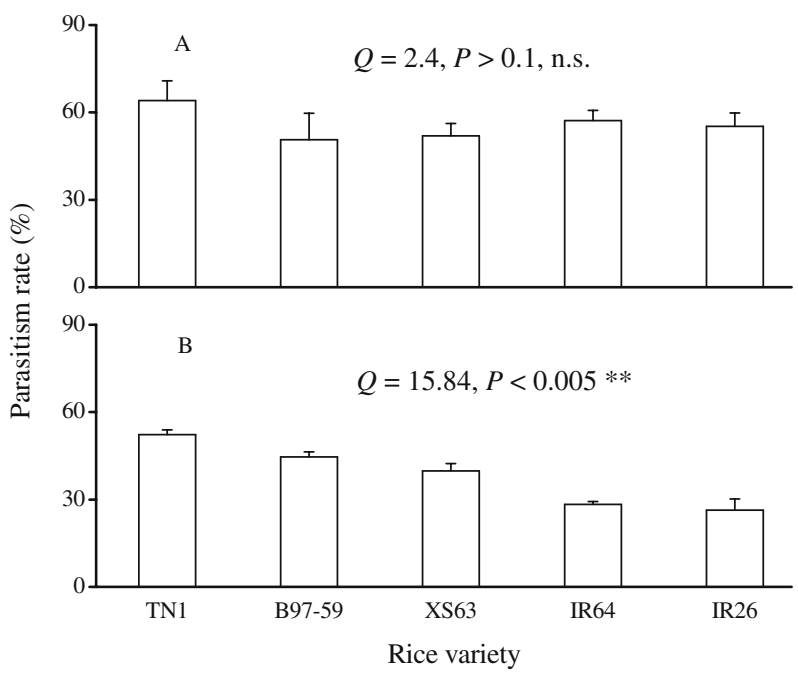

varieties within a particular group (IR64 vs. IR26 or Bing 97-59 vs. Xiushui 63), they showed no preference (Fig. 3). However, in two cases, significant preferences were observed between varieties from different groups (Fig. 3). Parasitoids preferred TN1 (group 1) and Bing 97-59 (group 3) over IR26 (group 2), but were equally attracted to TN1 and Bing 97-59 (Fig. 3).

\section{Field Experiment}

In the first field experiment, no significant difference was found in parasitism of $N$. lugens eggs on Shanyou 63 plants that were surrounded by JA-treated plants of different varieties (Fig. 4A). However, in the second experiment, there were significant differences (Fig. 4B). These reflected the differences in attractiveness of the varieties that had been observed in the olfactometer experiments (Fig. 3). Parasitism was highest on plants that were surrounded by TN1, followed by those on plants that were surrounded by Bing 97-59 (85.3\% of that surrounded by TN1) and Xiushui 63 (76.0\% of TN1), and lowest on plants surrounded by IR26 (50.4\% of TN1) and IR64 (54.2\% of TN1) (Fig. 4B).

\section{Discussion}

Varietal or genotypic differences in herbivore-induced volatiles have been recorded for several plant species (Loughrin et al., 1995; Turlings et al., 1998; Krips et al., 2001; Degen et al., 2004). Here, we show such differences in induced profiles among rice varieties (Table 2; Fig. 2). The assignment of the varieties to different groups on the basis of the induced volatile profiles (Table 1; Fig. 2) is consistent with the genetic backgrounds of these varieties (Table 1). For instance, varieties Bing 97-34, Bing 97-59, and Xiushui 63, all of which have a Bing 8961 parent in their pedigrees, shared similar profiles (Fig. 2). The sharing of parents such as IR24 and TKM6, which is the case for IR26 and IR64, also resulted in similar profiles, confirming that the volatiles emitted from varieties are genetically determined. 
Volatiles released from both TN1 and Bing 97-59 were more attractive to the parasitoid than those from variety IR26, whereas TN1 and Bing 97-59 were equally attractive (Fig. 3). Moreover, the parasitoid did not distinguish between the volatiles from IR26 and IR64, and those from Bing 97-34 and Bing 97-59 (Fig. 3). A comparison of their profiles (Table 2) does not provide much insight into which compounds may have been responsible for the observed differences in attractiveness. Linalool is a candidate that is attractive to A. nilaparvatae (Lou, 1999). 2-Heptanone, 2-heptanol, and methyl salicylate seem less likely to be important because they were released in considerable amounts by some of the least attractive varieties. The importance of specific plant volatiles for attraction of natural enemies is documented. For example, the lacewing (Chrysopa carnea), a predator of small insects, was caught more in traps containing $\beta$-caryophyllene than in traps that contained caryophyllene oxide, bisabolene, or limonene (Flint et al., 1979). When exposed to individual chemicals in an olfactometer, the predatory mite Phytoseiulus persimilis was attracted to linalool, methyl salicylate, $(E)$ - $\beta$-ocimene, and (3E)-4,8-dimethyl-1,3,7-nonatriene (Dicke et al., 1990). (E)- $\alpha$-Bergamotene increased Manduca sexta egg predation rates on Nicotiana attenuata by a generalist predator Geocoris pallens (Kessler and Baldwin, 2001). Recently, Kappers et al. (2005) demonstrated that the predatory mite P. persimilis is attracted by $(E)$-nerolidol or (3E)-4,8-dimethyl-1,3,7-nonatriene released from transgenic Arabidopsis thaliana plants. Similarly, transformation of Arabidopsis with a sesquiterpene synthase gene from maize resulted in the constitutive release of a blend of sequiterpenes, which made the transformed plant attractive to a parasitoid of lepidopteran larvae, but the parasitoid had to learn the volatiles during an oviposition experience (Schnee et al., 2006). In general, the identities of key attractants for parasitoids remain largely unknown (D'Alessandro and Turlings, 2006), and common herbivore-induced compounds may not be as important for attraction as usually assumed (D'Alessandro and Turlings, 2005).

We have previously shown that parasitism rates of $N$. lugens eggs by A. nilaparvatae on plants surrounded by JA-treated plants are significantly higher than those surrounded by control plants (Lou et al., 2005a). Here, we compared the effect of JA-treated plants of various rice varieties on parasitism. The clear and significant differences found in the second field experiment nicely matched the differences in attraction of the parasitoid that were found in the olfactometer bioassay. The average percentage parasitism $(55.82 \pm 2.63)$ in the first field experiment was significantly higher than that $(38.29 \pm 2.27)$ in the second time $(t=5.05$, $d f=48, P<0.001)$. This suggests a higher population density of the parasitoid in the field during the first field experiment. Parasitoids may interfere with each other intraspecifically or interspecifically, and the degree of interference increases with the increase in population density. Parasitoids and predators may also use volatiles to avoid intraspecific or interspecific competition (Janssen et al., 1995, 1997; Fatouros et al., 2005). Therefore, stronger interference among parasitoids under high population density might explain why there was no difference in parasitism rates among varieties in the first field experiment. From the results of the second experiment, however, it is clear that rice varieties with appropriate volatile profiles might enhance the effectiveness of the parasitoid in the field.

Many parasitoids have a keen ability to learn to respond to a specific odor by associating the odor with hosts or host feces (Lewis and Tumlinson, 1988; Vet and Groenewold, 1990; Turlings et al., 1993b). The parasitoids used here had emerged from $N$. lugens eggs on plants of variety Shanyou 63, and they had been in contact with this host plant before they were tested. The field experiments with potted plants were conducted in fields with the variety Jialeyou 2, on which the parasitoids would also have had experiences during the experiment. It is possible that the observed differences in attraction and parasitism were due to similarities or differences in volatile profiles between the $N$. lugens-infested rice varieties 
that the wasps experienced and the JA-treated experimental plants. We did not compare the volatile profiles of these varieties, and an effect of learning cannot be ruled out. This does not interfere, however, with the general conclusion that differences in volatile profiles and preferences for certain odors can be used to enhance the parasitism rate of $A$. nilaparvatae.

Only few studies have demonstrated the importance of herbivore-induced odor emissions outside the laboratory (Scutareanu et al., 1997; De Moraes et al., 1998; Thaler, 1999; Kessler and Baldwin, 2001; Lou et al., 2005a; Rasmann et al., 2005). One of those studies (Rasmann et al., 2005) also shows that the effectiveness of the natural enemies in the field can be enhanced by planting crop varieties that emit the appropriate volatile signal(s) from their roots. The results reported here represent a first example of how varietal differences in leaf volatiles affect tritrophic interactions in the field, implying that induced rice volatile emissions can be manipulated to enhance the control potential of egg parasitoids.

Acknowledgments We thank Wenwen Song, Guoxin Zhou, and Xia Wang for assistance with laboratory work. The study was sponsored by the Ministry of Science and Technology of China (973) (G2000016208), the National Natural Science Foundation of China (30270233, 30370960), the Program for New Century Excellent Talents of the Ministry of Education of China (NCET-04-0534), and the Innovation Research Team Program of the Ministry of Education of China (IRT0355).

\section{References}

Bukovinszky, T., Gols, R., Posthumus, M. A., Vet, L. E. M., and Van Lenteren, J. C. 2005. Variation in plant volatiles and attraction of the parasitoid Diadegmasemiclausum (Hellén). J. Chem. Ecol. 31:461-480.

Cheng, J. and He, J. 1996. Rice Insect Pests. China Agricultural Press, Beijing.

D'Alessandro, M. and Turlings, T. C. J. 2005. In Situ modification of herbivore-induced plant odours: A novel approach to study the attractiveness of volatile organic compounds to parasitic wasps. Chem. Senses 30:739-753.

D'Alessandro, M. and Turlings, T. C. J. 2006. Advances and challenges in the identification of volatiles that mediate interactions among plants and arthropods. Analyst 131:24-32.

De Moraes, C. M., Lewis, W. J., Paré, P. W., Alborn, H. T., and Tumlinson, J. H. 1998. Herbivoreinfested plants selectively attract parasitoids. Nature 393:570-573.

Degen, T., Dillmann, C., Marion-Poll, F., and Turlings, T. C. J. 2004. High genetic variability of herbivore-induced volatile emission within a broad range of maize inbred lines. Plant Physiol. 135:1928-1938.

DiCKE, M. 1999. Specificity of herbivore-induced plant defences, pp. 43-59, in D. J. Chadwich and J. Good (eds.). Insect-Plant Interactions and Induced Plant Defence. Novartis Foundation Symposium 223. Wiley, Chichester, United Kingdom.

Dicke, M., Sabelis, M. W., TAKabayashi, J., Bruin, J., and Posthumus, M. A. 1990. Plant strategies of manipulating predator-prey interactions through allelochemicals: Prospects for application in pest control. J. Chem. Ecol. 16:3091-3118.

Fatouros, N. E., Van Loon, J. J. A., HordiJK, K. A., Smid, H. M., and Dicke, M. 2005. Herbivoreinduced plant volatiles mediate in-flight host discrimination by parasitoids. J. Chem. Ecol. 31:20332047.

Flint, H. M., SAlter, S. S., and Walters, S. 1979. Caryophyllene: An attractant for the green lacewing. Environ. Entomol. 8:1123-1125.

Fritzsche-Hoballah, M. E., TAmò, C., and Turlings, T. C. J. 2002. Differential attractiveness of induced odors emitted by eight maize varieties for the parasitoid Cotesia marginiventris: Is quality or quantity important? J.Chem. Ecol. 28:951-968.

HalitschKe, R., Schittko, U., Pohnert, G., Boland, W., and Baldwin, I. T. 2001. Molecular interactions between the specialist herbivore Manduca sexta (Lepidoptera, Sphingidae) and its natural host Nicotiana attenuata. III. Fatty acid-amino acid conjugates in herbivore oral secretions are necessary and sufficient for herbivore-specific plant responses. Plant Physiol. 125:711-717. 
HeAth, R. R. and Manukian, A. 1992. Development and evaluation of systems to collect volatile semiochemicals from insects and plants using a charcoal-infused medium for air purification. J. Chem. Ecol. 18:1209-1226.

Hopke, J., Donath, J., Blechert, S., and Boland, W. 1994. Herbivore-induced volatiles: The emission of acyclic homoterpenes from leaves of Phaseolus lunatus and Zea mays can be triggered by a $\beta$ glucosidase and jasmonic acid. FEBS Lett. 352:146-150.

Janssen, A., VAn Alphen, J. J. M., SABelis, M. W., and BAKKeR, K. 1995. Specificity of odour-medeated avoidance of competition in Drosophila parasitoids. Behav. Ecol. Sociobiol. 36:229-235.

Janssen, A., Bruin, J., Jacobs, G., SchraAg, R., and Sabelis, M. W. 1997. Predators use volatiles to avoid prey patches with conspecifics. J. Anim. Ecol. 66:223-232.

Kappers, I. F., Aharoni, A., Van Herpen, T. W. J. M., Luckerhoff, L. L. P., Dicke, M., and BouWMEESTER, H. J. 2005. Genetic engineering of terpenoid metabolism attracts bodyguards to Arabidopsis. Science 309:2070-2072.

Kessler, A. and BALDWIN, I. T. 2001. Defensive function of herbivore-induced plant volatile emissions in nature. Science 291:2141-2144.

Krips, O. E., Willems, P. E. L., Gols, R., Posthumus, M. A., Gort, G., and Dicke, M. 2001. Comparison of cultivars of ornamental crop Gerbera jamesonii on production of spider mite-induced volatiles, and their attractiveness to the predator Phytoseiulus persimilis. J. Chem. Ecol. 27:1355-1372

LEWIS, W. J. and Tumlinson, J. H. 1988. Host detection by chemically mediated associative learning in a parasitic wasp. Nature 331:257-259.

LOU, Y. 1999. Role of infochemicals in host selection behavior of Anagrus nilaparvatae Pang et Wang. Ph. D. dissertation, Zhejiang University, Hangzhou, China.

Lou, Y., Du, M., Turlings, T. C. J., Cheng, J., and Shan, W. 2005a. Exogenous application of jasmonic acid induces volatile emissions in rice and enhances parasitism of Nilaparvata lugens eggs by the parasitoid Anagrus nilaparvatae. J. Chem. Ecol. 31:1985-2002.

Lou, Y., MA, B., and Cheng, J. 2005b. Attraction of the parasitoid Anagrus nilaparvatae Pang et Wang to rice volatiles induced by the rice brown planthopper Nilaparvata lugens (Stål). J. Chem. Ecol. 31:23572372.

Loughrin, J. H., Potter, D. A., and Hamilton-Kemp, T. R. 1995. Volatiles emitted by different cotton varieties damaged by feeding beet armyworm larvae. J. Chem. Ecol. 21:1217-1227.

MA, B., LOU, Y., and CHENG, J. 2004. Effects of some biotic factors on activities of the volatiles emitted from rice plants infested by the rice brown planthopper, Nilaparvata lugens (Stål). J. of Zhejiang Univ. (Agriculture and Life Science) 30(6):589-595.

Rasmann, S., Köllner, T. G., Degemhardt, J., Hiltpold, I., Töpfer, S., Kuhlmann, U., Gershenzon, J., and TURINGS, T. C. J. 2005. Recruitment of entomophatogenic nematodes by insect-damaged maize roots. Nature 434:732-737.

Rubia-Sanchez, E., Suzuki, Y., Miyamoto, K., and Watanabe, T. 1999. The potential for compensation of the effects of the brown planthopper Nilaparvata lugens (Stål) (Homoptera: Delphacidae) feeding on rice. Crop Prot. 18:39-45.

Schnee, C., Köllner, T. G., Held, M., Turlings, T. C. J., Gershenzon, J., and Degenhardt, J. 2006. A maize terpene synthase contributes to a volatile defense signal that attracts natural enemies of maize herbivores. Proc. Natl. Acad. Sci. USA. 103:1129-1134.

Scutareanu, P., Drukker, B., Bruin, J., Posthumus, M. A., and Sabelis, M. W. 1997. Volatiles from psylla-infested pear trees and their possible involvement in attraction of anthocorid predators. $\mathrm{J}$ Chem. Ecol. 23:2241-2260.

TAKABAYASHI, J. and DiCKE, M. 1996. Plant-carnivore mutualism through herbivore-induced carnivore attractants. Trends Plant Sci. 1:109-113.

THALER, J. S. 1999. Jasmonate-inducible plant defences cause increased parasitism of herbivores. Nature 399:686-688.

TURLINGS, T. C. J. and WÄCKERS, F. L. 2004. Recruitment of predators and parasitoids by herbivoredamaged plants, pp. 21-75, in R. T. Cardé and J. Millar (eds.). Advances in Insect Chemical Ecology. Cambridge University Press.

Turlings, T. C. J., McCall, P. J., Albornl, H. T., and Tumlinson, J. H. 1993a. An elicitor in caterpillar oral secretions that induces corn seedlings to emit chemical signals attractive to parasitic wasps. J. Chem. Ecol. 19:411-425.

Turlings, T. C. J., WÄCKers, F. L., Vet, L. E. M., Lewis, W. J., and TumLinson, J. H. 1993b. Learning of host-finding cues by hymenopterous parasitoids, pp. 51-78, in D. R. Papaj and A. C. Lewis (eds.). Insect Learning. Ecology and Evolutionary Perspectives. Chapman \& Hall, New York.

Turlings, T. C. J., Lengwiler, U. B., Bernasconi, M. L., and Wechsler, D. 1998. Timing of induced volatile emissions in maize seedlings. Planta 207:146-152. 
Van Den Boom, C. E. M., Van Beek, T. A., Posthumus, M. A., Groot, A., and Dicke, M. 2004. Qualitative and quantitative variation among volatile profiles induced by Tetranychus urticae feeding on plants from various families. J. Chem Ecol. 30:69-89.

VET, L. E. M. and DiCKE, M. 1992. Ecology of infochemicals use by natural enemies in a tritrophic context. Annu. Rev. Entomol. 37:141-172.

Vet, L. E. M. and Groenewold, A. W. 1990. Semiochemicals and learning in parasitoids. J. Chem. Ecol. 16:3119-3135.

Watanabe, T. and Kitagawa, H. 2000. Photosynthesis and translocation of assimilates in rice plants following phloem feeding by the planthopper Nilaparvata lugens (Homoptera: Delphacidae). J. Econ. Entomol. 93:1192-1198.

Zhu, L., ZhU, C., Weng, Q., HuAnG, Z., and He, G. 2004. Research progress on brown planthopper resistance genes in rice. Hubei Agric. Sci. 1:19-24. 